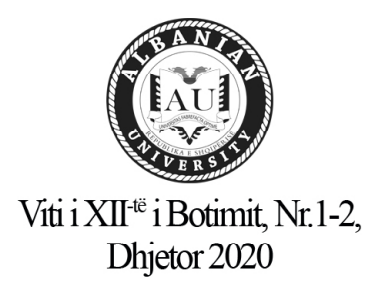

\title{
MARRËDHËNIET E PRINDËRVE ME FËMIJËT E PARË Sibela Ymeraj*
}

*Msc Psikologji e Përgjithshme, Albanian University

Adresë kontakti: s.ymeraj@albanianuniversity.edu.al

\section{Përmbledhje}

Objektivi: Qëllimi i këtij studimi është eksplorimi i mëtejshëm i marrëdhënies së ngushtë prind-fëmijë, por duke u fokusuar vetëm tek marrëdhënia e prindërve më fëmijën e parë. Cila është marrëdhënia që kanë krijuar këta prindër me fëmijën e tyre të parë?

Ajo që ka qenë shtysa kryesore për mua në realizimin e këtij studimi, ka qenë fakti që unë personalisht jam fëmija i parë në familje. Marrëdhënia apo raporti që unë kam me prindërit krahasuar me vëllain tim është krejt ndryshe nga marrëdhënia që ai ka me prindërit. Kjo ka qenë një nga arsyet që mua më ka bërë përshtypje dhe prandaj kam marrë nismwn për ta bërë pjesë të studimit tim, eksplorimin e mëtejshëm të kësaj marrëdhënie.

Metodologjia: Intervista gjysmë e strukturuar. Për mbledhjen e të dhënave kam përdorur intervistën gjysmë të strukturuar dhe kam intervistuar: Prindërit (nënën ose babain), fëmijët e parë në familje.

Intervistat me personat kyç të studimit i kam zhvilluar në ambientet e shtëpisë së të intervistuarve, kështu që ambienti ishte i përshtatshëm për një bashkëbisedim të qetë dhe po ashtu njohja e terrenit nga ana e prindërve përbënte avantazh për mua pasi ata mund të shpreheshin më lirshëm dhe intervistat të ishin më frytdhënëse për studimin.

Në disa raste më është dashur të dal pak nga korniza e pyetjeve të parapërgatitura, për të qëndruar dhe hulumtuar më shumë rreth një çështjeje të caktuar.

Për realizimin e këtij studimi kam përdorur modelin e kampionimit pa probabilitet dhe kam përdorur më konkretisht kampionimin e konveniencës. Kam zgjedhur pikërisht këtë metodë kampionimi sepse ishte metoda më e përshtatshme për studimin tim. Ky lloj kampionimi ishte lehtësisht i disponueshëm dhe i arritshëm për mua si studiuese. 
Sibela Ymeraj

\section{Pyetjet kërkimore:}

A ndryshojnë marrëdhëniet që krijojnë prindërit me fëmijët e parë krahasuar me fëmijët e tjerë në familje? Përse ndryshojnë këto marrëdhënie? Cilat janë disa nga arsyet dhe disa nga karakteristikat dalluese të këtyre fëmijëve krahasuar me fëmijët e tjerë në familje? A ndikojnë këto karakteristika në krijimin e kësaj mardhënieje? A krijojnë fëmijët e parë lidhje apo marrëdhënie më të forta me prindërit krahasuar me fëmijët e tjerë?

Rezultatet: Përgjithësisht rezultatet e studimit kanë përmbushur pritshmëritë e mia lidhur me marrëdhënien prind-fëmijë, në bazë të radhës së lindjes. Rikonfirmova faktin që fëmijët e parë kanë kërkesë më të lartë llogarie nga prindërit, në thuajse të gjitha fushat e jetës. Ajo që më bëri përshtypje ishte lidhja mes këtij kontrolli dhe nivelin e ankthit tek fëmija i parë. Fjalë çelës: Fëmijë i parë $=>=>$ Fëmijë i sapolindur, foshnjë djalë apo vajzë që nga lindja deri në moshën 18 vjeç do të konsiderohet fëmijë. Fëmijë i parë do të quhet çdo fëmijë që është i pari nga radha e lindjes së fëmijëve. Prind=> Prind quhet nëna dhe babai përkundrejt fëmijëve të tyre.

Mardhënie prindërore $=>$ Marrëdhëniet sociale, afektive, emocionale që krijojnë prindërit me fëmijët e tyre. Lidhje e fortë $=>$ Afrim i dy individëve apo i dy palëve në një marrëdhënie të ngushtë dhe të drejtpërdrejtë. Përgjegjësi=> Organizuesi dhe drejtuesi i punës së disa personave të tjerë në një moment të caktuar. Detyrimi që ka dikush për t’u përgjigjur për punën dhe veprimet e veta.

\section{PARENT-FIRST CHILD RELATIONSHIPS}

\section{Abstract}

Objective: This study aims to further explore the close parent-child relationship but focused solely on the relationships betwen parents and their first child. What features parents' relationship with their first child?

What specifically sparked my interest in conducting this study, was the fact that I myself, am the first child in my family. My relationship or rapport with my parents is rather different in comparison with my brother's relationship with them. This was precisely one of the reasons that caught my fancy and made me take the initiative to engage in further exploring such a relationship.

Methodology: I employed the semi-structured interview whereby for data collection I actually interviewed: Parents (mother or father), first children in the family.

Was conducted an interview with the key people in the study at the interviewees' home environment, so as to be suitable for a comfortable conversation; in addition, the parents 
MARRËDHËNIET E PRINDËRVE ME FËMIJËT E PARË

familiarity with such a terrain was an advantage for me as they could express themselves quite freely thus making the interviews more productive for the study.

On several occasions, I had to skip over the questionnaire framework already prepared in advance, to draw on and inquire more into a certain issue.For the realization of this study, I used the non-probability sampling model and more concretely, the convenience sampling method. I chose exactly this sampling method because it was the most suitable one for my study. This type of sampling was readily available and accessible to me as a researcher.

\section{Research questions:}

Do the relationships between parents with their first children differ from those with other children in the family? Why do such relationships differ? What are some of the reasons and some of the distinct features of these children compared to other children in the family? Do such features affect the creation of this relationship? Do first children in a family build up stronger bond or relationships with their parents compared to other children?

Results: The results of the study generally met my expectations regarding the parent-child relationship, based on the birth order. Through this study, I re-confirmed that the first children in a family are more prone to higher demands and expectations from their parents, in almost all areas of life. What impressed me most, was the link between such a control and the level of anxiety felt in the first child.

Key terms: First child $=>$ firstborn, a baby boy or girl from birth to the age of 18 will be considered a child. The first child in a family will be called any child who comes first in the birth order of children within that family. Parent $=>$ Parent is called a mother and a father of their children. Parental relationships $=>$ The social, affective, emotional relationships that parents create with their children. Strong bond $=>$ The affinity between two individuals or two parties in a close and direct relationship. Responsible person $=>$ The organizer and work manager at the workplace of some other people at a certain moment. Someone's obligation to be accountable for his/her own work and actions.

\section{HYRJA}

Studimi i marrëdhënies prind - fëmijë dhe anasjelltas është cilësuar si veprimtari e vështirë për shumë studiues të ndryshëm, dhe kjo për disa arsye: Marrëdhëniet që krijojnë fëmijët me prindërit janë të ndyshme nga familja në familje, nuk mund të gjenden receta të gatshme për mënyrat se si mund të sillemi me prindërit apo me fëmijët, gjithçka varet nga mjedisi dhe personaliteti i gjithësecilit. ${ }^{1,2}$ Megjithatë shumë studiues të ndryshëm e kanë lëvruar këtë fushë duke na dhënë studime me përfundime interesante. 
Sibela Ymeraj

Duke marrë shkas nga disa prej këtyre studimeve unë jam përpjekur të ngre studimin tim, që lidhet me marrdhënien që krijojnë prindërit me fëmijët e parë, sa të forta janë këto marrëdhënie dhe karakteristikat e fëmijëve që ndikojnë në krijimin e saj. Disa prej këtyre studimeve unë i kam përmendur edhe në studimin që kam realizuar. Marrëdhënia e prindërve me fëmijët e parë është një marrëdhënie sa e ngrohtë aq edhe e veçantë, sikurse jo vetëm me këta fëmijë por edhe me fëmijët e tjerë në familje. ${ }^{3,4}$ Marrëdhënia që prindërit krijojnë me fëmijët e tyre varet së tepërmi dhe nga karakteristikat e fëmijës, dhe për të eksploruar me tepër këtë marrëdhënie, më është dashur të eksploroj edhe për një pjesë të këtyre karakteristikave apo veçorive të fëmijëve të parë.

Disa nga çështjet e tjera që unë kam trajtuar, përveç karakteristikave të fëmijëve të parë dhe marrëdhënies së tyre me prindërit janë: A kanë ndryshuar marrëdhëniet që kanë krijuar prindërit me fëmijët e parë në vite? A xhelozojnë fëmijët e parë? A mund ta quajmë fëmijën e parë eksperiment prindëror? Pyetje interesante por që kanë marrë përgjigje në fund të studimit.Prindërit dhe fëmijët janë një binom i pandarë i shoqërisë njerëzore por ajo që unë personalisht do të doja shumë të theksoja në fillim të këtij është: Të bëhen të mundura prezantime të një panorame më specifike për marrëdhëniet që krijojnë prindërit shqiptarë me fëmijët e tyre.4 Në këtë mënyrë të mund ta eksplorojmë më mirë shoqërinë tonë dhe zanafillën e saj që nga familja, e njëkohësisht dhe të mundohemi të ruajmë anët më pozitive të kësaj marrëdhënie.

\section{Rregulli i lindjes}

Adlerit i takon merita si teoricien i parë që trajtoi ndikimin e hershëm te fëmija jo vetëm të prindërve dhe të rriturve të tjerë, por edhe të motrave dhe vëllezërve gjithashtu. Konsiderata e tij për ndikimin e vëllezërve dhe motrave dhe radha me të cilën kanë lindur është me sa duket arsyeja pse Adleri është nga më të njohurit. Adler e konsideron rregullin e lindjes së fëmijëve një tjetër prej atyre ideve orientuese-trillime të dobishme që kontribojnë të kuptosh njerëzit, pse ata sillen dhe veprojnë në një mënyrë të caktuar. ${ }^{5}$

Fëmija i vetëm ka më shumë mundësi se të tjerët të llastohet, mbi të gjitha prindërit e fëmijës së vetëm kanë vënë të gjitha vezët e tyre në një shportë si të thuash, dhe ka të ngjarë të kenë më shumë kujdes të veçantë, nganjëherë kujdes të mbushur me shqetësim të tepruar, për krenarinë dhe gëzimin e tyre. Nëse prindërit janë abuzivë, nga ana tjetër, fëmijës do t’i duhet ta durojë këtë abuzim, e vetmja gjë e cila është shumë e vështirë. ${ }^{5}$

Fëmija i parë e fillon jetën si një fëmijë i vetëm, megjithë përkujdesin ndaj tij. "Për fat të keq", sapo gjërat bëhen të rehatshme, arrin fëmija i dytë dhe e "rrëzon nga froni". Në fillim fëmija mund të luftojë për pozicionin e tij të humbur. Ai mund të përpiqet të sillet si i vogël. 
Disa bëhen të pabindur dhe kryengritës, disa të tjerë të zymtë dhe të rezervuar. Adler më shumë se kushdo besonte se fëmijët e parë kanë probabilitet me të lartë për t’u bërë fëmijë me probleme. Më konkretisht fëmijët e parë mund të preken nga zhvillimi i parakohshëm. Ata tentojnë të jenë relativisht të vetmuar dhe më konservatorë se sa fëmijët e tjerë në familje. ${ }^{5}$ Fëmija i dytë është në një situatë krejt të ndryshme: Ai ka fëmijën e parë si një lloj "lideri" dhe përpiqet të bëhet tërësisht konkurues, vazhdimisht përpiqet të kalojë fëmijën më të rritur. Ata shpesh kanë sukses, por shumë ndjejnë sikur gara nuk është përfunduar kurrë dhe kanë prirjen të ëndërrojnë për vrapim të përhershëm pa arritur asgjëkundi. Tjetri, fëmija i mesit, do të tentojë të bëhet i ngjashëm me fëmijën e dytë, ndonëse secili mund të fokusohet në "konkurrues" të ndryshëm. ${ }^{5}$

Fëmija i sapolindur ka gjasa të jetë më shumë i përkëdhelur në familjen me më tepër se një fëmijë. Megjithatë, është i vetmi që nuk rrëzohet kurrë nga froni. Dhe kështu fëmijët e sapolindur bëhen sërish burim i mundimshëm i fëmijëve me probleme, nganjëherë pas fëmijëve të parë. Nga ana tjetër, i sapolinduri gjithashtu mund të ndihet shumë inferior me cilindo më të rritur dhe "si pasojë" superior. Por me gjithë ata "lider" përpara, edhe i sapolinduri mund të nxitet t'ua kalojë të gjithë atyre.

Kush është fëmija i parë, i dytë, i sapolindur, nuk është kaq e qartë sa mund të duket. Nëse ka një shtrirje kohore të gjatë midis fëmijëve ata mund të mos ta shohin veten dhe njëri-tjetrin në të njëjtën mënyrë sikur të ishin më afër në kohë. Ka tetë vjet diferencë midis vajzës time të parë dhe të dytë dhe tre ndërmjet të dytës dhe të tretës; kjo gjë do ta bëjë vajzën time të parë një fëmijë të vetëm, të dytën fëmijën e parë dhe të tretën të dytë dhe të sapolindur!

Edhe nëse disa nga fëmijët janë djem dhe disa janë vajza përbën një dallim gjithashtu. Fëmija i dytë e cila është vajzë mund të mos ta marrë vëllain e saj më të madh, si dikë për të konkurruar me të: djali në familjen e vajzave mund të ndihet më shumë si fëmijë i vetëm, e kështu me radhë. Si gjithçka në sistemin e Adlerit, rregulli i lindjes duhet të kuptohet në kuadrin e rrethanave të veçanta të individëve. ${ }^{5}$

Fëmijët e vetëm shquhen për përsosmëri dhe për faktin se arrijnë gjithmonë objektiva ambiciozë. Gjithmonë në kërkim të vëmendjes, kanë nevojë për aprovimin e prindërve apo miqve.

Studimet u atribuojnë fëmijëve të parë një koeficient inteligjence ${ }^{1.5}$ pikë më të madh se të tjerëve. Fëmija i madh shpesh duhet të kujdeset edhe për të tjerët që vijnë pas tij dhe kjo i stimulon atij aftësitë njohëse dhe kapacitetin e të nxënit. ${ }^{6}$

Studime të tjera thonë se vetëm 1 për qind e karakterit ndikohet nga radha e lindjes. Faktorë të tjerë si historia e jetës, gjenetika, mjedisi dhe aspekti fizik, kanë rol më të madh përcaktues. $^{7}$ 
Sibela Ymeraj

Sipas pjesës më të madhe të psikologëve, fëmijët dallohen kryesisht me strategjinë që kanë për të tërhequr vëmendjen. Fëmijët e parë preferojnë të mbrojnë autoritetin, ndërsa më të vegjëlit preferojnë rrugën e rebelimit. ${ }^{8}$

“Çdo fëmijë mëson të interpretojë rolin që ka në familje. Fëmija i parë mbahet në kontroll të plotë. Por pak nga pak, pasi vijnë vëllezërit e motrat e tjerë, prindërit qetësohen”, thotë për "Huffington Post" doktori Kevin Leman, psikolog dhe autori i librave "Libri i renditjes së lindjes" dhe“Avantazhi i të qënit fëmija i parë". ${ }^{9,7}$ Por si e interpreton shkenca këtë ndryshim? Sipas dr. Leman, fëmijët e parë kanë tendencën të arrijnë objektivat, janë studentë të shkëlqyer, dhe arrijnë të fitojnë pozicionin e liderit. Shumë prej presidentëve të SHBA-së, për shembull, kanë pasur rolin e vëllait të madh. "Ata janë standard referimi për të tjerët", thotë dr. Leman. ${ }^{10,11}$

Por fëmija i parë është edhe konformist, sipas një studimi të 2009, publikuar në gazetën Child Development. ${ }^{9}$ Konformizmi shërben për të kënaqur prindërit. "Përgjegjësia, konkurrenca, konservatizmi janë karakteristika të tjera tipike, ndërsa fëmijët më të vegjël kërkojnë, në të kundërt, të krijojnë hapësirë nëpërmjet rebelimit”, thonë psikologët belg Vassilis Saroglou dhe Laure Fiasse, autor të një studimi të publikuar në Personality and Individual Differences. $^{12}$

II. Avantazhet dhe disavantazhet e të qënit fëmijë i parë në një familje.

\section{Avantazhet.}

$\varnothing$ Kujdesi prindëror për rritjen dhe edukimin e fëmijës së parë është më i lartë krahasuar me fëmijët e tjerë në familje.

$\varnothing$ Vëmendja dhe përkushtimi nga ana e prindërve, e gjyshërve apo edhe e të afërmve të tjerë është më e madhe, gjë që e bën fëmijën të jetë gjithmonë në qendër të gjithçkaje.

$\varnothing$ Fakti që fëmijët e parë krijojnë marrëdhënie me shumë individ njëherësh pra me prindërit, gjyshërit, të afërmit apo edhe persona të tjerë, i bën të ndihen më social dhe njëkohësisht më të rritur krahasuar me fëmijët e tjerë.

\section{Disavantazhet.}

Ø Fëmija i parë mbingarkohet me përgjegjësi, gjë që i shkakton stres dhe ankth në nivele më të larta krahasuar me fëmijët e tjerë.

$\varnothing$ Prindërit e fëmijëve të parë kanë pritshmëri më të larta për ta, gjë e cila në rastin e mospërmbushjes së pritshmërive shkakton pakënaqësi si te prindërit, ashtu dhe tek fëmijët.

$\varnothing$ Prindërit mund ta mbytin fëmijën me një rol shumë të theksuar mbrojtës, me një bombardim dashurie ndaj tij duke ia realizuar të gjitha dëshirat apo duke i bërë kufizime në liritë e tij; 
MARRËDHËNIET E PRINDËRVE ME FËMIJËT E PARË

mundet që fëmija të mbetet një fëmijë që nuk beson lehtë.

$\varnothing$ Fakti që për një periudhë kohe fëmijët e parë rriten si fëmijë të vetëm dhe ardhja në jetë e një fëmije tjetër e rrëzon nga "froni", e detyron këtë fëmijë që të bëjë çdo lloj sjellje (si të rregullta ashtu edhe jo të rregullta) për të rifituar sërisht vëmendjen.

$\varnothing$ Fëmija i parë bëhet burim eksperimenti për prindrit dhe ato veprime që kanë qenë të gabuara tek fëmija i parë mund të mos përsëriten tek fëmija i dytë, por nga ana tjetër kjo lloj sjellje shkakton zemëratë tek fëmija i parë.

III. Lidhja prind-fëmijë

Që nga çasti i lindjes foshnja kërkon lidhjen me nënën. Ky është qëllimi i lëvizjeve të saj. Shumë muaj me radhë nëna luan një rol jashtëzakonisht të rëndësishëm në jetën e saj (foshnjes); gati se plotësisht gjithçka varet nga ajo. Në këtë situatë zhvillohen fillet e aftësive për jetë në bashkësi. Nëna i ofron foshnjës lidhjet e para me një krijesë tjetër njerëzore, dhe interesi i parë në dikë tjetër se vetëvetja. Ajo është ura e parë për jetë në bashkësi, dhe një foshnje, e cila nuk mund të krijoj lidhje me nënën e saj apo ndonjë njeri tjetër, i cili e merr rolin e saj, mbarimi (i foshnjës) do të ishte i pashmangshëm. ${ }^{13}$

Kjo lidhje është aq e thellë dhe e gjerë sa që ne në vitet e mëvonshme kurrë nuk do të jemi në gjendje çfarëdo tipari ta cilësojmë me siguri si ndikim i trashëgimisë. Çdo prirje që ne do mund ta konsiderojmë si trashwguese është përshtatur nga nëna, e ushtruar, e formuar dhe gjithmonë është tejkaluar. Shkathtësitë e saj, apo mangësia e tyre kanë ndikuar në të gjitha mundësitë ekzistuese në fëmijën. ${ }^{14}$

Si ndihen fëmijët e parë në familje?

Përgjithësisht fëmijët e parë në familje ndiejnë një marrëdhënie ndryshe mes prindërve dhe fëmijëve të tjerë në familje. Ata thonë që prindërit për çdo gjë ja u hedhin fajin këtyre si më të mëdhenjtë që janë. Kërkesa e llogarisë është shumë herë më e madhe ndaj meje se ndaj motrës, shprehet një nga vajzat e intervistuara. ${ }^{15}$

\section{Përfundime.}

Fëmijët e parë kanë marrëdhënie më të ngushta e më të forta me prindërit, dhe me gjithë të afërmit e tjerë të rrethit familjar. Ata kanë për një periudhë të caktuar kohore gjithë vëmendjen e prindërve dhe kur vjen në jetë fëmija i dytë këtë vëmendje ata nuk duan ta ndajnë me askënd. Fëmijët e parë janë më të dashur sesa fëmijët e tjerë në familje. Në shumicën e rasteve kanë rezultate me të larta akademike krahasuar me fëmijët e tjerë në radhën e lindjes. Prindërit shpesh bëjnë dallime mes fëmijëve duke e veçuar fëmijën e parë nga fëmijët e tjerë në familje, falë disa karakteristikave të veçanta të personalitetit që ai gëzon. Fëmijët e parë 
Sibela Ymeraj

marrin dhe mbingarkojnë veten me shumë përgjegjësi në familje, këto përgjegjësi herë ja atribuojnë vetvetes sepse ndihen më të mëdhenj në moshë, dhe herë të tjera këto përgjiegjësi ju atribuohen nga prindërit. Fëmijët e parë janë më të dobët dhe më të ndjeshëm ndaj ankthit dhe stresit, fakti që ata mund të mbingarkohen me përgjegjësi është një ndër shkaktarët kryesorë të tij. Prindërit e fëmijëve të parë janë më tepër kontrollues dhe ndikojnë më shumë tek fëmija i parë sesa tek fëmijët e tjerë në familje. Fëmijët e dytë, tretë e me radhë për nga radha e lindjes e kanë më të thjeshtë të bëjnë gjërat që ju pëlqejnë se fëmijët e parë. Prindërit kanë mësuar ta menaxhojnë më mirë ankthin te fëmijët e dytë në krahasim me fëmijën e parë. Pritshmëritë e prindit si në anën akademike, ashtu dhe në atë sjellore, janë më të larta tek fëmija i parë.

\section{Referenca}

1. Naomi Aldort, Phd Aldort (2006). Raising our children, raising ourselves, Book Publishers 2. Phyllis Heath, (2005). Parent-child Relations: History, Theory, Research and Context, Hall and Merrill Education

3. Dorothy M. Devore (2006). Parent-child Relations: New Research, Nova Publishers

4. Keneth H. Rubin, Ock Boan Chung (2013). Parenting Beliefs, Behaviors, and Parent-Child Relations: A Cross-Cultural Context, Psychology Press

5. Alfred Adler Edited by Henry T. Stein, ph.d (2006). The Collected Clinical of Alfred Adler: The General System of Invidual Psychology, Printed in the United States of America

6. Tony Buzan (2003). Brain Child: How Smart Parents Make Smart Kids 7. http://edi-un.weebly.com/prinder-feumlmij.html 8. http://newmedia-ks.com

9. Katherine E. Krohn (2000). Everything You Need to Know about Birth Order, The Rosen Publishing Group

10. DR.C. George Boeree (2006). Personality Theories, Shippens burg University

11. Cliff Isaacson with Meg Schneider (2004). The Birth Order Effect for Couples, Fair Winds press, Gloucenter, Massachuetts

12. Gerald Koocher, Annete La Greca (2010). The Parents Guide to Psychological First Aid, Oxford University Press

13. Edmond Dragoti (2008). Psikologjia Sociale, Toena 14. http://www.gazetaexpress.com/ mistere/lidhja-misterioze-prind-femije-17853/

15. Linda A. Pollock (1987). A Lasting Relationship: parents and children over three centuries, University Press of New England 